\title{
Building a case for accessing service provision in child and adolescent mental health assessments.
}

Michelle O’Reilly *

University of Leicester

The Greenwood Institute of Child Health

Westcotes Drive

Leicester

LE3 OQU

Mjo14@le.ac.uk

*author for correspondence

Nikki Kiyimba

University of Chester

Westminster Building

Parkgate Road

Chester

CH1 4BJ

n.kiyimba@chester.ac.uk

Jessica Nina Lester

Department of Counseling \& Educational Psychology,

Inquiry Methodology Program,

201 N. Rose, Suite 4060,

Bloomington, IN, 47405-1006

jnlester@indiana.edu

Submitted to: Discourse studies

Word count: 6988 (excluding title page)

Short title: Building a case for services

Acknowledgements: We extend our gratitude to all of the families and mental health practitioners who consented to be recorded for research, and to our broader research team who helped in the recruitment of families and collection of data; especially Khalid Karim, Victoria Lee and Ian Hutchby. We also thank the Heart of England Hub for funding the pilot study that contributed to the success of this project.

\section{Biographical note:}

Dr Michelle O'Reilly is an Associate Professor of Communication in Mental Health at the University of Leicester, and Research Consultant for Leicestershire Partnership NHS Trust. Her research interests are in child mental health, therapy and discourse.

Dr Nikki Kiyimba is a Clinical Psychologist and Senior Lecturer of Therapeutic Practice for Psychological Trauma at the University of Chester. Her research interests are mental health, trauma and discourse.

Dr Jessica Lester is an Associate Professor of Inquiry Methodology at Indiana University. Her research interests are in social interaction in schools, clinics and communities. She has a particular interest in autism.

The authors have no conflict of interest to declare. 
journals@discourses.org. Please write on the subject line: Paper for DISCOURSE STUDIES. The file should be attached to an accompanying message, in which you should identify yourself with your full name and address, and address the editor by name, one of the ways to distinguish your submission from -- unfortunately all too frequent -- SPAM. For the same reason, it is also strongly recommended that you add your full name to your email address in the header of your message when that address does not clearly identify who you are; if necessary please edit the settings of your e-mail program accordingly. Do not attach your paper to a message without a personalized letter to the editor. 


\begin{abstract}
In everyday conversations, people put forward versions of events and provide supporting evidence to build a credible case. In environments where there are potentially competing versions, case-building may take a more systematic format. Specifically, we conducted a rhetorical analysis to consider how in child mental health settings, families work to present a credible 'doctorable' reason for attendance. Data consisted of video-recordings of 28 families undergoing mental health assessments. Our findings point to eight rhetorical devices utilised in this environment to build a case. The devices functioned rhetorically to add credibility and authenticate the case being built, which was relevant as the only resource available to families claiming the presence of a mental health difficulty in the child were their spoken words. In other words, the 'problem' was something constructed through talk and therefore the kinds of resources used were seminal in decision-making.
\end{abstract}

Key words: Case building, mental health, children, adolescents, rhetoric, conversation analysis 


\section{Introduction}

Mental health is a global priority, especially as related to children and young people; in part, because mental health conditions are increasingly framed as conditions of the young (Howard et al., 2017). Estimates suggest that $50 \%$ of mental health conditions in adults were present before the individual was 15-years-old (Kessler et al., 2005). Preventative action, early intervention, and a focus on recovery using multi-agency and multidimensional approaches are needed (Department of Health, 2015). Statistics within the UK suggest that $12.8 \%$ of 5 to-19-year-olds have a diagnosable mental health condition (NHS Digital, 2017), with international statistics suggesting a global prevalence of 10-20\% (Kieling et al., 2011). As these rates are argued to be increasing, child and adolescent mental health is becoming increasingly recognized as a critical area for research. This is especially important as it has been noted that mental health conditions involve a complex nexus of interrelated relations between society, family, school and peers (Weare, 2000).

In most Western societies the mental health status of children and young people are firstly the concern of parents, whereby via a General Practitioner, the child is referred to be assessed by a mental health clinic. In the UK, this referral is to the Child and Adolescent Mental Health Service (CAMHS), designed to assess, diagnose and treat those with emotional, behavioural or neurodevelopmental conditions (Karim, 2015). In CAMHS, a multidisciplinary approach is taken, typically involving different mental health specialists (ibid). The initial assessment usually necessitates that the parent/guardian and other family members attend with the identified child (Hartzell et al., 2010), as the presence of the family allows for a broader understanding. The initial assessment is designed to screen for symptoms by identifying risks and an initial formulation of what the presenting problem may be (Mash and Hunsley, 2005). It is during this process that the institutional requirements for information-gathering are followed, questions posed, and an assessment agenda followed (O'Reilly et al., 2015; Thompson and McCabe, 2016).

During assessments, families present concerns that their child has a mental health problem. This typically follows a long process of waiting for a referral to specialist services. Families generally wait an average of 3.1 years from when the parent(s) first identifies concerns to receiving a diagnosis (Shanley et al., 2008). In primary care, research has indicated that patients on attending present a 'doctorable' reason for being there; that is, that their 
appointment was worthy because of the alignment between the problem and the institutional business (Heritage and Robinson, 2006). This is also the case in mental health settings, where families often position their child as the reason for attendance and specifically in assessments, where problem presentation forms a key agenda item (O’Reilly et al., 2015). Discovering the reasons for attendance is a central institutional task and has been referred to as the 'complaint' phase of an appointment (ten Have, 2001). In that sense, this is an occasion for the patient to actively provide an account for their reason for visiting and offer candidate diagnoses for their concerns (Heritage and Robinson, 2006). In the initial mental health assessment, this aspect of the appointment is a multi-party task. Here the child/young person and their parents are questioned together, and the process is one through which family members organise how they present their case as doctorable.

\section{Aims}

In mental health clinics, families have longer appointment times to present their case than General Practice, and consequently these environments are rich in examples of case building sequences. Furthermore, because of the multiparty dimension, there are potentially different versions that may be discussed, and the case building may take a more systematic format, as speakers orient to the other parties to present their counter-argument. The focus of this paper is to examine how family members within a CAMHS environment collectively or separately build their case rhetorically to persuade the professionals that the child has a diagnosable and clinically relevant condition.

\section{Method}

Language-based analytic approaches provide an essential form of empirical evidence and an important research base for mental health, that are becoming more widely accepted (O'Reilly and Lester, 2017). We therefore utilised rhetorical analysis (Billig, 1987) to explore how parents present their child's doctorable need for specialist mental health services.

\section{Rhetorical analysis}

“Any reasoned argument seeks to exclude, or persuade against counter-views"

(Billig, 1987, p.2) 
A rhetorical community is both formed by and through language (Kastely, 1988). A rhetorical approach points to the argumentative aspects of discourse (Billig, 1987), and allows a focus on the relationship between speakers and their audiences (White, 1985). In this approach, the analyst focuses on the ways in which a certain assessment is put together to counter any possible or established alternative (Billig, 1988). Our rhetorical analysis drew upon the principles of applied conversation analysis (CA). Notably, the sequential organisation was relevant to the persuasive case being made, and, more generally, the institutional business being conducted had applied importance. When undertaking rhetorical analysis, the methods of CA are useful to illuminate how interlocutors go about the argumentative task of presenting their rhetorically complex perspective(s) (Billig, 1987). CA scholars generally examine how talk is ordered and functions to perform social actions (Hutchby and Wooffitt, 2008). More particularly, applied CA provides a detailed way by which to explore social interaction in institutional settings, potentially focusing on the communication between practitioners and clients (Lester and O'Reilly, 2019). We acknowledge that rhetorical analysis emphasises relationships between differing positions and CA emphasises sequential organisation (Potter, 1996), but the alignment between the two is nonetheless well-suited. This alignment of approaches is valuable for exploring the persuasive social actions performed in an assessment setting, as parents manage their stake in the potential outcomes, and in presenting their assessment relevant reasons for requiring an appointment.

We utilised naturally occurring data, which allowed us to capture what happens in real world practice (Potter, 2002) and identify recurrent and systematic patterns (Drew et al., 2001). Further, through co-analysis via data sessions, we sought to promote rigour (Kiyimba et al, 2019). This was facilitated by the production of detailed Jefferson transcripts (Jefferson, 2004), representing talk in a way that supports readers in better understanding how things were said, as well as what was said (Hepburn and Bolden, 2017).

\section{Context and participants}

Data were collected through the UK CAMHS, where a purposeful sample of all consenting first assessment appointments were recruited, excluding urgent referrals. The appointments followed a general agenda, moving through introductions to reasons for attendance and 
problem presentation to decision-making and delivery (O'Reilly et al., 2015). Children and young people were assessed by a minimum of two practitioners (except in one case), and all 29 practitioners in the team were included. Each assessment lasted approximately 90 minutes, and 28 families participated. Participating children were $64 \%$ boys and $36 \%$ girls, with a mean age of 11 years, ranging from 6-to-17 years.

\section{Ethics}

Ethics approval was provided by the UK National Research Ethics Service. All participants, including young participants, gave consent/assent. Pseudonyms were used to protect anonymity.

\section{Findings}

In this paper, we refer to the rhetorical social action of incrementally and collaboratively presenting a version of the child's problem as case-building; that is, that the child has a doctorable mental health problem. In so doing, families used rhetorical devices as a mechanism for inoculation against potential counter arguments or reasoning. Linguistically, rhetoric is defined as the art of persuasive speaking or writing (dictionary.com), and in social interaction, interlocutors may use evaluative rhetoric to present a version as 'factual' (Wiggins and Potter, 2008). That is, speakers present themselves in ways that positions them as unbiased (Billig, 1991; Potter, 1996 b). Rhetoric therefore is argued to be complex, argumentative, contextual, fluid, and reflexive (Condor et al., 2013).

Although ostensibly mental health assessments are not adversarial, for all parties there is much at stake. For families there is a desire to access to services, and for practitioners there is a responsibility to judiciously allocate resources. Within these encounters, families frequently used persuasive techniques to build a case for the necessity of support. In this context, rhetorical devices were the 'available means' that speakers drew upon to build the factuality of their accounts. Rhetorical devices were cumulatively and collectively used to form an evidence synthesis to support the case being built. We separate our discussion of the findings below into the main rhetorical devices used by participants to strengthen the evidence for their case, as outlined in Table 1. While we do not offer an exhaustive list of the discursive 
resources used to present their case, the rhetorical devices we share here reflect the most common devices found within our dataset.

Table 1: Rhetorical Devices Used by Participants to Strengthen the Evidence for Their Case.

\begin{tabular}{|l|l|}
\hline \multicolumn{1}{|c|}{ Rhetorical Device } & $\begin{array}{l}\text { This refers to the use of quantifiable markers, including } \\
\text { recency, frequency, longevity and severity of the symptoms or } \\
\text { behaviours. }\end{array}$ \\
\hline Quantification & $\begin{array}{l}\text { This refers to the narration of specific examples of certain } \\
\text { kinds of behaviour. }\end{array}$ \\
\hline Epistemic corroboration & $\begin{array}{l}\text { This refers to the reporting of an opinion of an expert other that } \\
\text { supports the case being built. }\end{array}$ \\
\hline Reported speech & $\begin{array}{l}\text { This refers to reporting the words, as they were spoken, by } \\
\text { someone else in the manner that they were spoken. }\end{array}$ \\
\hline Dispositional & $\begin{array}{l}\text { This refers to making claims that there is an inherent or } \\
\text { fundamental aspect that has been ever present. }\end{array}$ \\
\hline Sudden change & $\begin{array}{l}\text { This refers to the presentation of an extreme and unexpected } \\
\text { change in behaviour. }\end{array}$ \\
\hline I thought it was x now y & $\begin{array}{l}\text { This refers to the contrast between something they thought was } \\
\text { ordinary 'x', to something they now believe is more } \\
\text { problematic 'y' }\end{array}$ \\
\hline case being built \\
\hline
\end{tabular}

i) quantification

The first category was labelled as 'quantification' and included various ways of quantifying aspects of the problem presentation. This included, longevity and severity of the behaviours/symptoms, and the recency and frequency of their presentation. Broadly, using quantities (e.g., frequencies) in communication often serves to provide an ostensibly more 'objective,' set of claims (Porter, 1996). Often in a clinical assessment, practitioners will initiate questions specifically designed to elicit this kind of information. However, the focus of this paper on case building directed our attention to those instances where the use of 
quantification as a rhetorical device was initiated by families themselves. The following extract is an example of a family-initiated description of the longevity of the problem.

Extract 1: Family 20 (female-11 years)

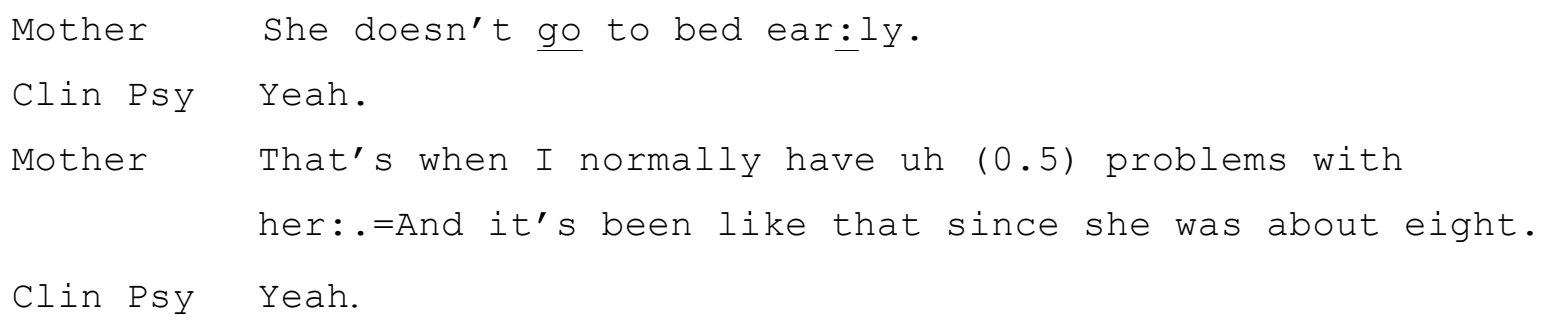

The child described by the mother was aged 11 years at the time of the assessment. Therefore, by stating that the problems began when the child was 'eight,' she demonstrated that the problem had been present for at least three years. After initiating the topic of the child's bedtime, the mother continued to both position this as a current problem by using present tense phrasing, such as 'I normally have uh (0.5) problems', and as a long-standing issue, by using latching at a Transition Relevance Place (Sacks et al., 1974) to add additional information about the longevity of the problem. While extract one illustrated an example of longevity, the following extract highlights the severity of the child's behaviour.

Extract 2: Family 9 (female-8 years)

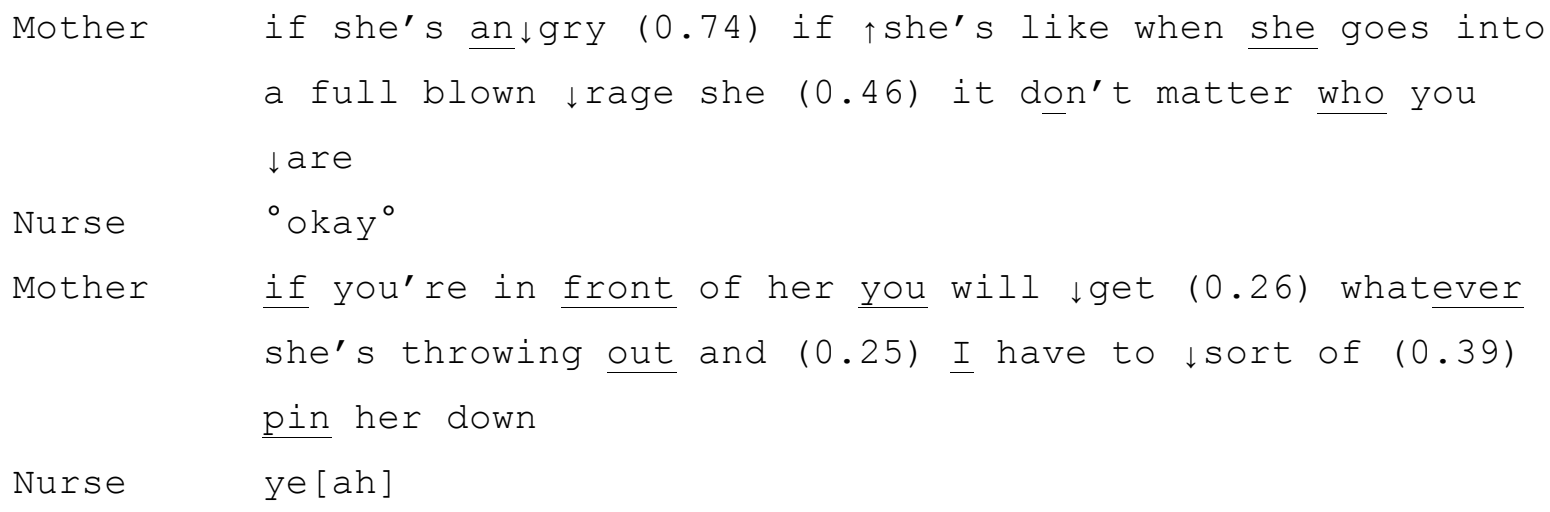

In building a case for the extremity of her child's behaviour as severe enough to be 'doctorable', the mother initiated a dialogue about the severity of her daughter's 'rage'. The social action appears to be a pathologizing of behaviour beyond what might be 'normally' expected of an 8-year-old girl. This was displayed through the rhetorical positioning of the 
anger being beyond the child's control. In other words, by reporting that 'it don't matter who you are', suggests that the child is non-discriminatory about where and in front of whom she exhibits the behaviour. The use of extreme case formulations (Pomerantz, 1986) packaged within idiomatic expressions, such as 'full blown rage,' work to support the quantification of the behaviour as severe and extreme. Additionally, by stating that physical restraint was a necessary recourse to manage her behaviour, 'have to pin her down' the mother further built her case for the child's need for professional services. A further quantification device functioned to initiate the relevance of the recency of behaviour, as illustrated in extract three.

Extract 3: Family 2 (male-15 years)

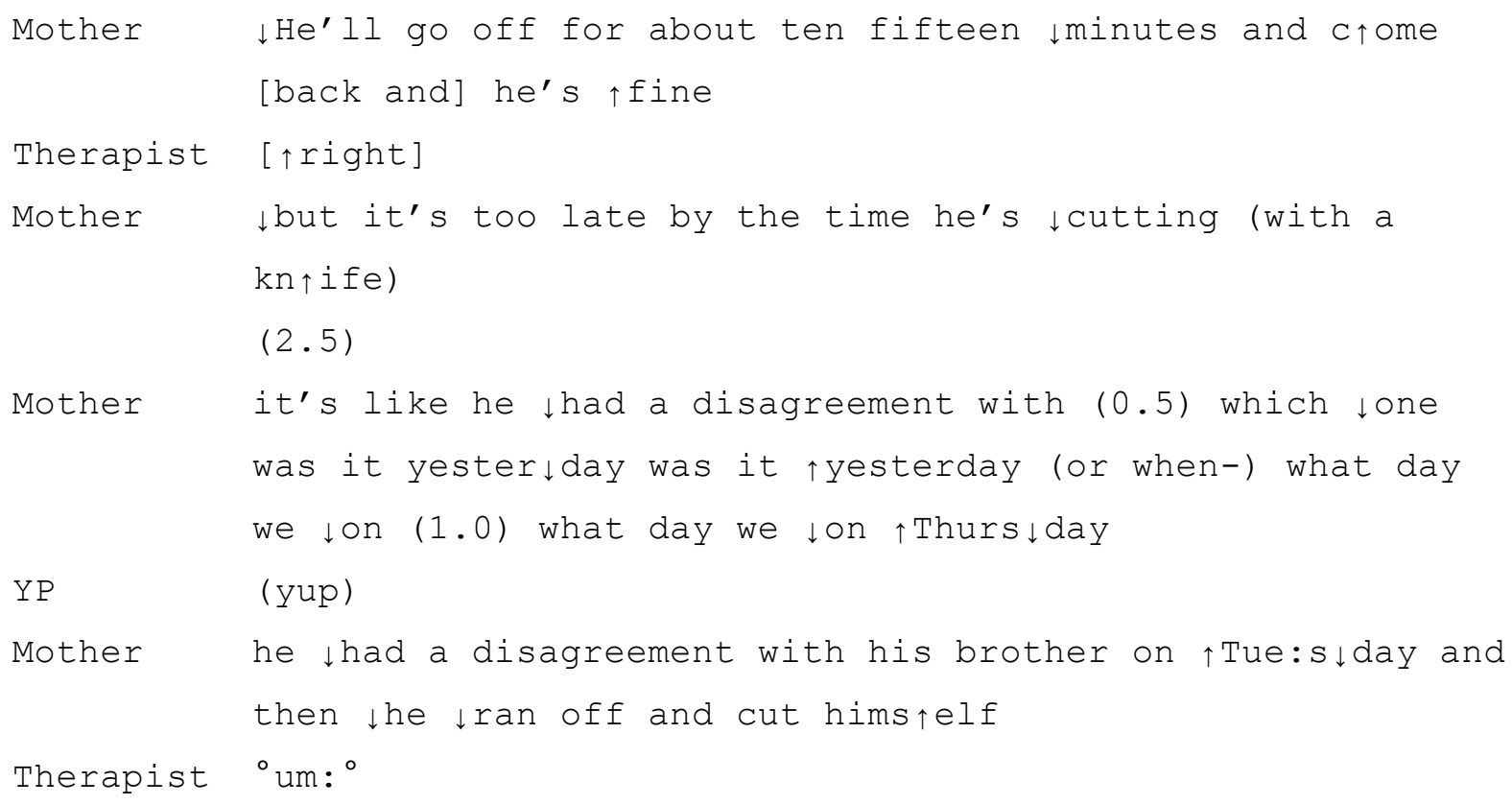

This extract opens with the mother of a 15-year-old male discussing his self-harming behaviour, presented in the continuous present tense, with 'he's cutting with a knife'. After making this strong statement about his behaviour, there was no immediate uptake from the therapist, demonstrated by the 2.5 second pause, and the mother continued with a specific recent example. Given the ambiguity of this pause, which may indicate either agreement or tacit resistance, the mother appears to intensify the case building about the doctorability of this problem presentation. This was done through the rhetorical device of recency, by demonstrating that this behaviour had occurred within the previous 48 hours of the appointment 'Thursday...Tuesday'. The last rhetorical resource used within quantification was that of frequency, as illustrated in extract four. 
Extract 4: Family 5 (female-6 years)

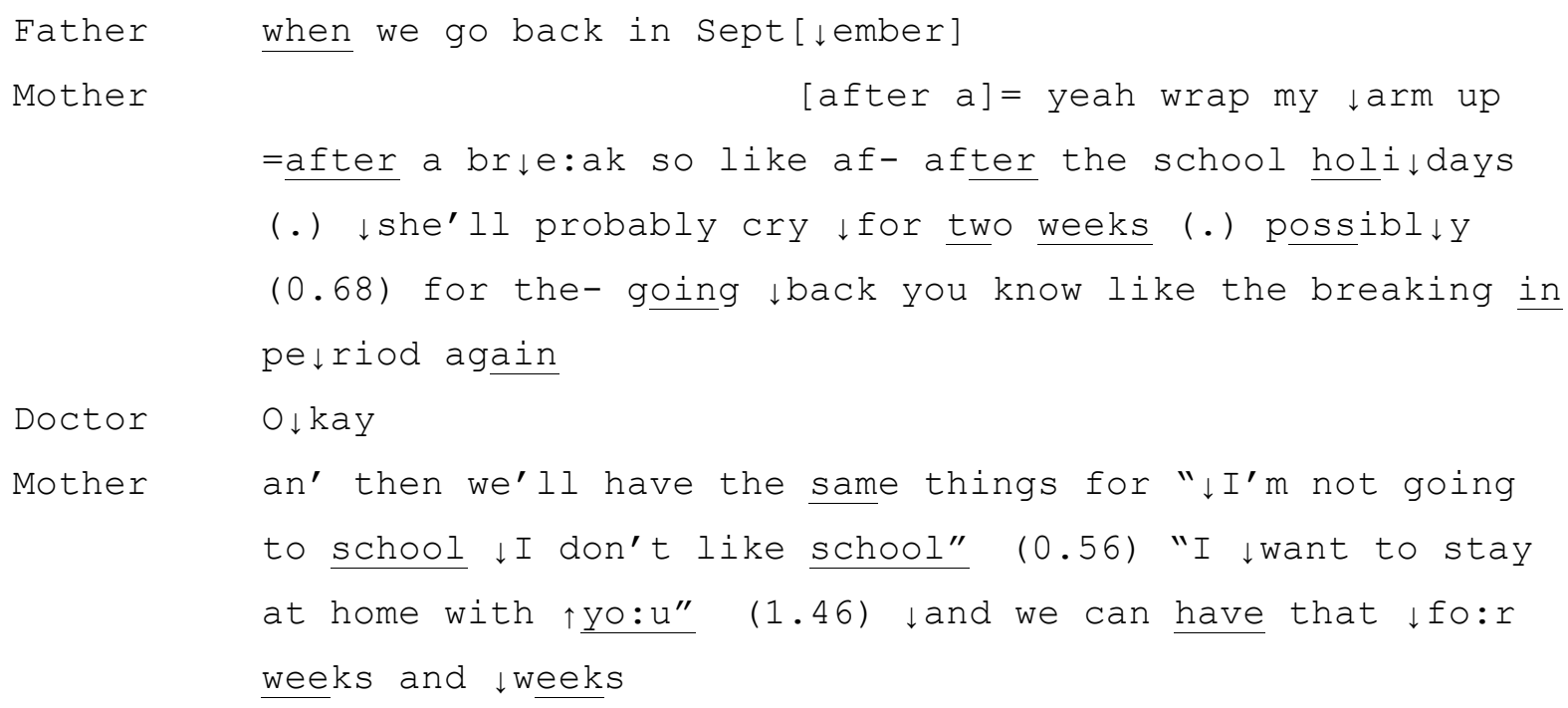

The unusualness of the child's behaviour was presented by the mother through her use of the frequency of the crying when the child returns to school. It could be normatively expected that a child of six-years-old might be upset at leaving her mother at the start of school. However, this would usually be expected to be short-term, whereas by using a quantification rhetorical device, the mother emphasised that the crying can go on 'for weeks and weeks. What this contributes to the persuasiveness of the case being built is the pathologising of the behaviour as being more extreme than may normatively be expected. This presents the behaviour as 'doctorable' and provides a rationale for requiring specialist services.

ii) Use of detail

The use of detail in talk is well-established as a rhetorical device in the CA literature. When speakers provide specific details about events or situations the function is to present the authenticity and factuality of the account (Potter, 1996). In these assessments, parents often enriched their accounts with specific details about the child's problematic behaviour or emotions and in so doing pointed to the abnormality. For example, in the following extract, the mother listed a series of specific descriptors congruent with the candidate diagnosis of Tourette's.

Extract 5: Family 20 (female-11 years) 


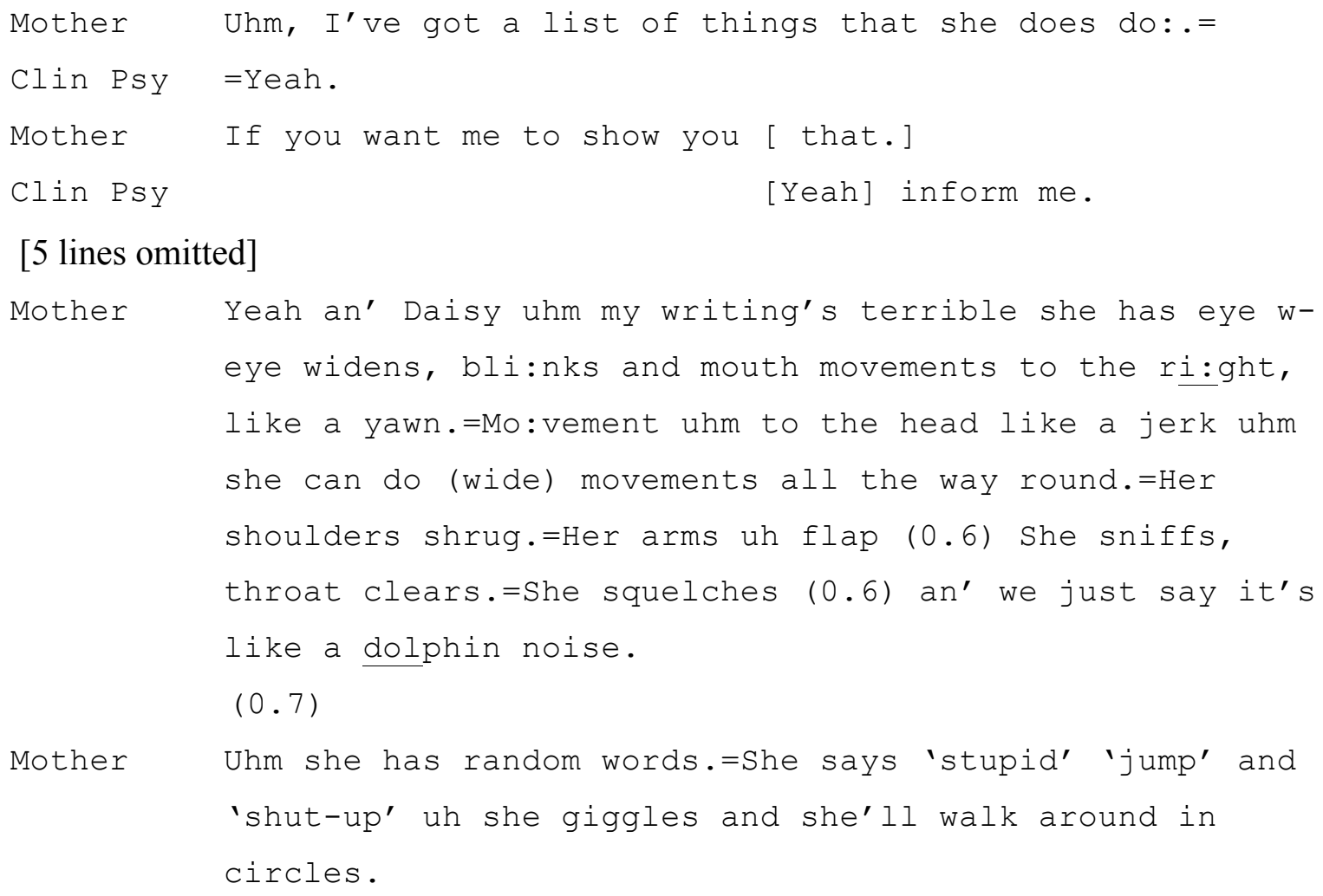

The mother's use of a pre-announcement (Sacks, 2004), that she had a 'list of things' that her daughter does, serves to signpost a number of descriptors of the behaviour that support the case being made. These descriptors cumulatively worked to increase the persuasiveness of the message by building a picture of the child's behaviour at home. The mother began by describing a range of movements; 'eye widens, blinks and mouth movements'. She also cited movements to the head in a jerky way and arm flapping. Additionally, she listed unusual noises; 'sniffs, throat clears' and 'squelches'. All of which might be congruent with a diagnosis of Tourette's. The specificity of the example words - 'stupid, jump and shut up'demonstrated to the clinical psychologist the randomness of the words uttered by the child. From a rhetorical perspective, the specificity of the words cited provides plausibility to the account being presented.

iii) Epistemic corroboration

The rhetorical device of epistemic corroboration relates to a category of actions which include reference to third parties who are positioned as experts. The rhetorical power of epistemic corroboration is that it presents a case that there is expert support for the position 
being taken by the speaker. For example, a speaker in a $\mathrm{K}+$ position is treated as having credibility to present a version from their expert stance (Heritage, 2012). In example 6, the 'expert other' that was cited, was the 'doctor' (GP).

Extract 6: Family 21 (Male-17 years)

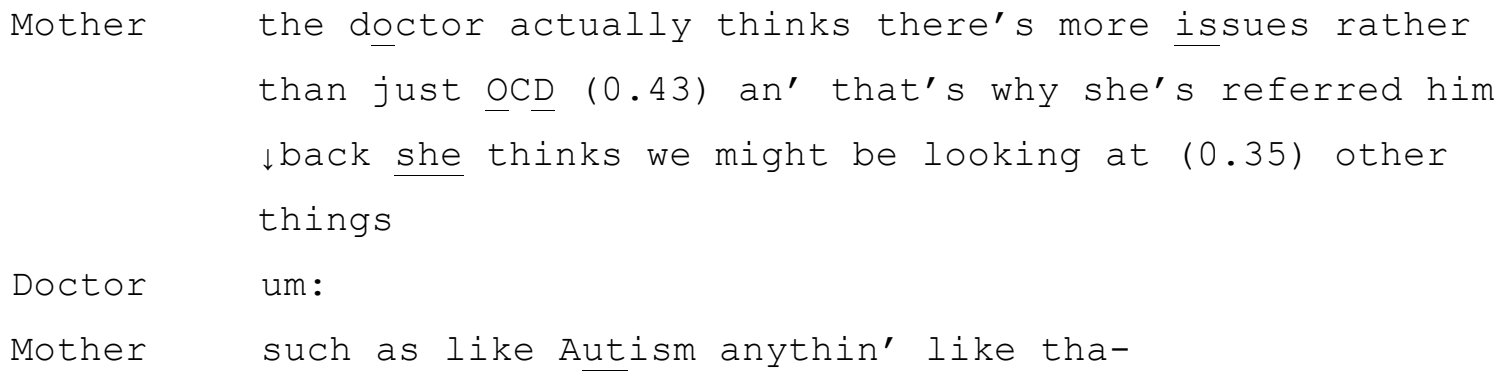

In preference to making a claim to a potential diagnosis of autism herself, the mother used the rhetorical device of using an 'expert other' to propose this as a possible diagnosis 'doctor actually thinks' . In doing so, she enhances the plausibility of the claim. The use of the discourse particle 'actually' functioned as an upgrade to the statement being made and marked the 'news' as informative or important (Clift, 2001). Thus, the use of this particle facilitated the factuality of the statement and indicated a contemporary relevance for the speaker (Schegloff, 1996). Juxtaposed with the doctor's action of a referral to specialist services, this promotes the possibility of 'autism' being a credible condition to explore in the assessment and promotes the insufficiency of the existing ' $O C D$ ' [Obsessive Compulsive Disorder] label. The mother therefore built her case by citing a professional expert in support of her suspicion, which corroborates the validity of her request for an assessment. In other words, by being a doctor, their epistemic position as a medic, enhances the persuasiveness of the case.

iv) reported speech

In these assessments, parents often quoted what their child had said in other environments. The rhetorical device of presenting the words as if spoken by the child, is referred to in the literature as reported speech. Reported speech has several features, including being displayed as sounding the same (via inflection, pace and intonation), and usually prefaced by third person references, like he- or she-said (Holt, 1996). It has been argued that the use of 
reported speech serves to authenticate the validity of a claim, and to fortify the rhetorical task (Wooffitt, 2001). In the following extract, reported speech was used collaboratively by both parents to re-enact a whole scene from a recent family interaction, as a way of presenting an example of the child's over-concern and anxiety about punctuality.

Extract 7: Family 3 (male-13 years)

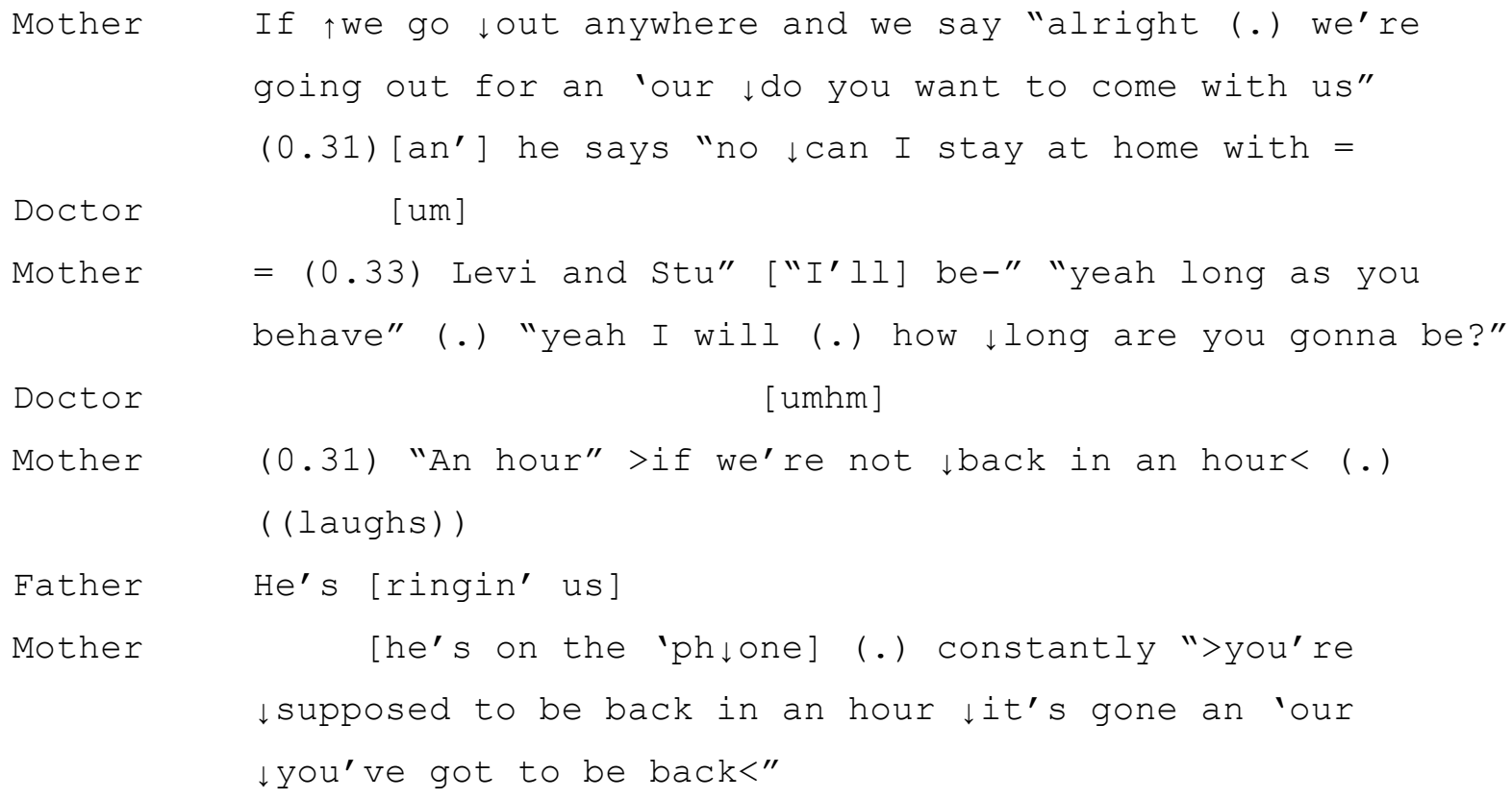

In opening the dialogue that occurred at the time of 'going out,' the mother in her first turn utilised reported speech with the typical preface of 'we said' and 'he said' to indicate whose speech was reported. However, in her second turn these prefaces were notably absent and the speech was enacted as occurring at the time without orienting to the current interaction. The temporary dropping of the interactional prefaces of 'we said' or 'he said' served to draw the listener into the reported interaction as if over hearing it in real time.

The crux of the topic in this extract was the child's over concern about the parents returning within the exactly specified time of an hour. Thus, in building their case for a doctorable reason for being present in the clinic, the parents highlight that the child reacts in ways that are unusual. This reaction to the 'hour' of time was positioned rhetorically as problematic. To enhance the credibility of this claim, the use of reported speech served a rhetorical function in presenting the case as more factual. 
v) Dispositional

This rhetorical device is similar to longevity within the quantification category. However, longevity is marked by a certain onset point which is often typified by a contrast of at or by a certain age; however, dispositional makes a claim to an ever-present, always there problematic or unusual characteristic. The following extract is an example of this rhetorical device.

Extract 8: Family 22 (male-11 years)

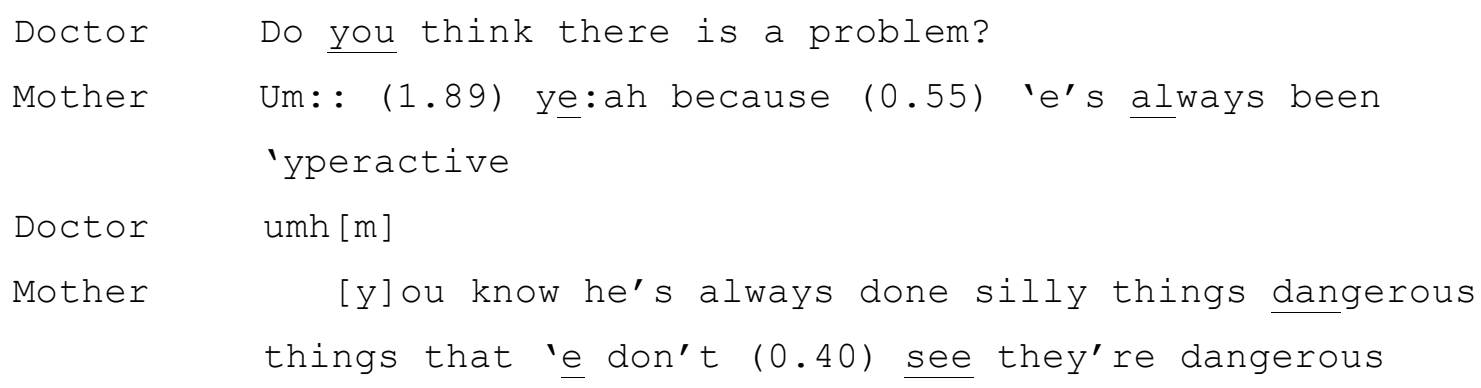

A characteristic feature of this device was the use of 'always' to conceptualise the dispositional nature of the issue. For example, the mother used the term twice, to report that her son has 'always been 'yperactive' and 'always done silly things dangerous things'. Using the word 'always' positioned the problem as a longstanding trait as opposed to a temporary phase in the child's development. Events that are described as instances of more generalised patterns are rhetorically persuasive by showing how routine they are (Edwards, 1995). By showing that something has always been present demonstrated its dispositional character as newsworthy; that is, the mundane is not reported as it is not worthy of reporting (Sacks, 1992). Here the case being built was that these aspects are non-ordinary and dispositional therefore needing access to services.

vi) Sudden change

In the dispositional rhetorical device, the strength of the argument lies in an implicit contrast between the child's dispositional nature that is being presented as abnormal and problematic, compared to a normal child's dispositional nature. However, in contrast, the sudden change rhetorical device implicitly contrasts the child's earlier normal behaviour with the child's 
current abnormal behaviour. The following example illustrates this contrast between what the child was implied to have been like compared to the child's behaviour now.

Extract 9: Family 4 (male-9 years)

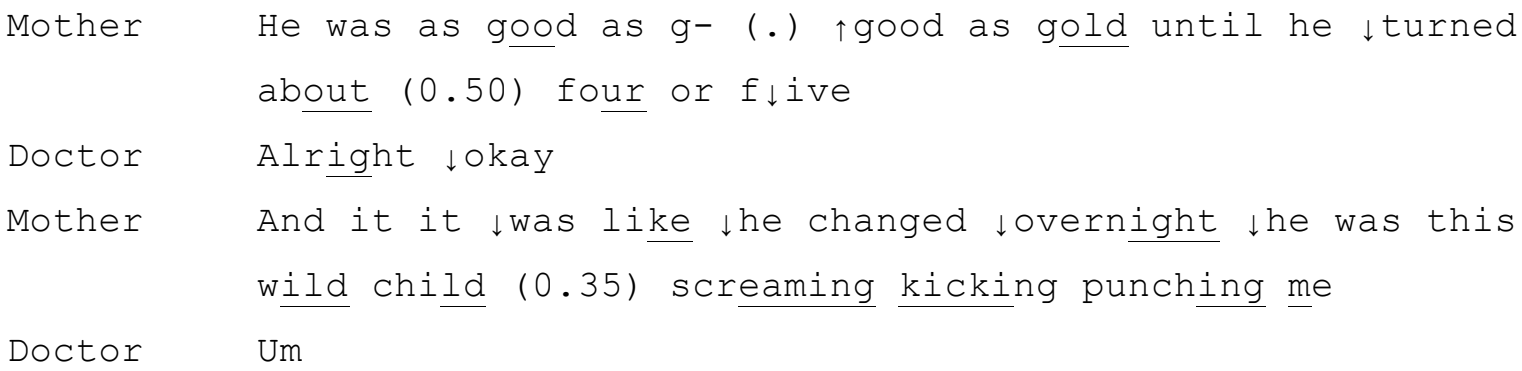

Using contrasting idiomatic expressions, 'good as gold' with 'wild child,' the mother presented two versions of the child. First, she invoked the stereotypical presentation of a child who is well behaved and easy to be with and second, she invoked the stereotypical presentation of a child who is out of control. In presenting these contrasting idioms as before and after, she presented a complaint about the current behaviour. The use of idiomatic expressions in conversation rhetorically function to summarise the complaint in a way that enhances its legitimacy (Drew and Holt, 1988). In this case, the mother not only presented her case as legitimate by contrasting idioms but bolstered it further with an extreme case formulation (Pomerantz, 1986). These extreme behaviours, which the mother described using the transitive verbs 'screaming kicking punching,' are clearly part of a case being built, namely that the child is violent. The notable aspect of this case building was the 'suddenness' of which the child began to display this violent behaviour, 'like he changed overnight.' The unusualness being highlighted was the extremity of change and immediacy of it.

vii) I thought it was ' $x$ ' now ' $y$ '

The rhetorical device of 'I thought it was x now y' has similarities with the rhetorical device proposed by Wooffitt (1991) - 'I was just doing x when y'. Wooffitt argued that the initial part of the device is utilised by a speaker to counter a potentially negative inference and the interactional and rhetorical task is achieved through the way in which the recollection is formulated. In a similar way, the ' $x$ ' in both instances relate to an inference about an experience which could have a normal or ordinary explanation. By posing this first, the 
rhetorical aspect of the device is that the more ordinary explanation has already been discounted and is therefore no longer available to the co-interlocutor to propose as a counter argument. The following extract illustrates a marked change in thinking of the mother, as she presented the idea that her daughter's behaviour can no longer be constructed as ordinary or normal.

Extract 10: Family 1 (female-13 years)

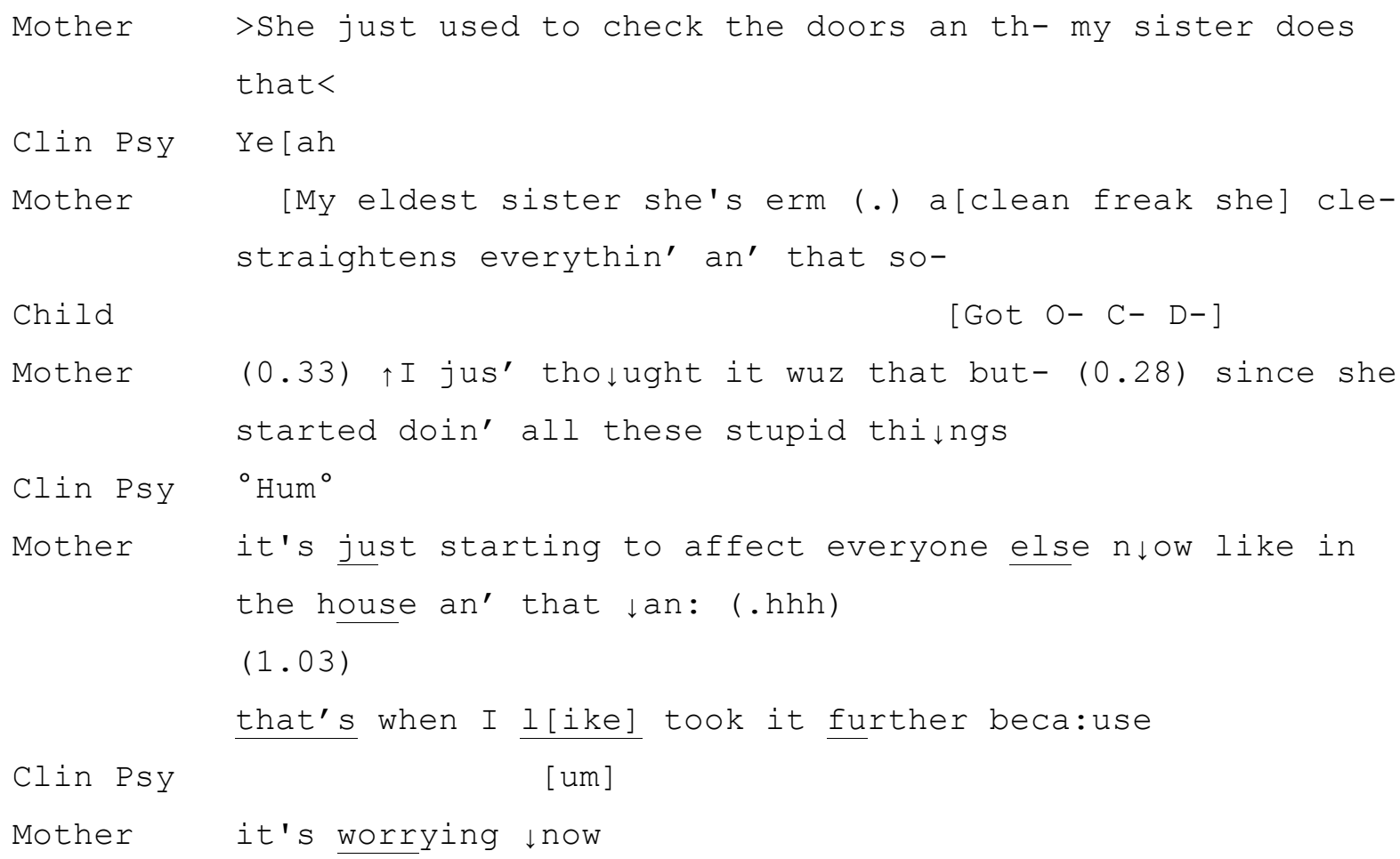

Here the mother formulated an initial description of the child's behaviour with the phrase 'used to check doors,' constructing it as non-concerning because her own 'sister does that.' In so doing, she highlighted a previous behaviour as one that other people do. In terms of the rhetorical device, such illumination functioned as 'I thought it was $\mathrm{x}$;' that is, in this case, the mother thought it was behaviour that was within the range of what would be normatively acceptable. However, the 'but y' aspect of the device can be seen as the mother contrasting the previous behaviour with current behaviour 'started doin' all these stupid things'. While not clarified within this extract what constitutes these 'stupid things,' were positioned as the reason for seeking help from the mental health service, with 'I like took it further' and as being 'worrying.' 
Notably, the mother employed the lexical particle of 'just' three times and these perform different social actions in their respective sequential positions. In the first two instances 'just' was used as a minimiser: 'just used to check doors' and 'I just thought it wuz that'. However, in the third instance, 'just' was used to refer to the recency of change in severity of the behaviour: 'it's just starting to affect everyone else'. The minimising use of just on those first two occasions served to rhetorically prevent a certain kind of reading of that behaviour in a way that presents the first part of a contrast. Playing down the concerning nature of the first part provided a platform to maximise the need for concern related to the current behaviour; that is, the second part of the contrast. By performing this contrast in this way, the newsworthiness of the second part of the contrast structure, both in terms of the needing help and the worrying nature of the behaviour, were emphasised.

\section{viii) Physical evidencing}

In initial assessments family members typically verbally reported witnessing the child's behaviour at home and in the child's social world, as evidencing their claim to the child's doctorable problem. Conversation analysts have argued that claims to directly witnessing something adds a dimension of legitimacy to the account (Hutchby, 2001), so presenting first-hand experience of the child's problematic behaviour does rhetorical business. As the assessing practitioners are often not direct witnesses to the behaviour (unless displayed in clinic, which is unusual), they rely predominantly on the accounts of family members. However, this is open to possible criticism of being biased by their stake and interest and their subjectivity or at least questioning of the validity of all information presented. Orienting to this possible counter-argument of bias, one way in which families arguably attempted to increase the objectivity of their account, was that they offered concrete physical evidence (albeit infrequently). This offered an opportunity for practitioners to become direct witnesses. In the following extract, the concrete evidence offered was a video-recording of the child's actions.

Extract 11: Family 26 (male-8 years)

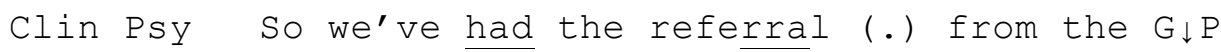
Mother Yeah 


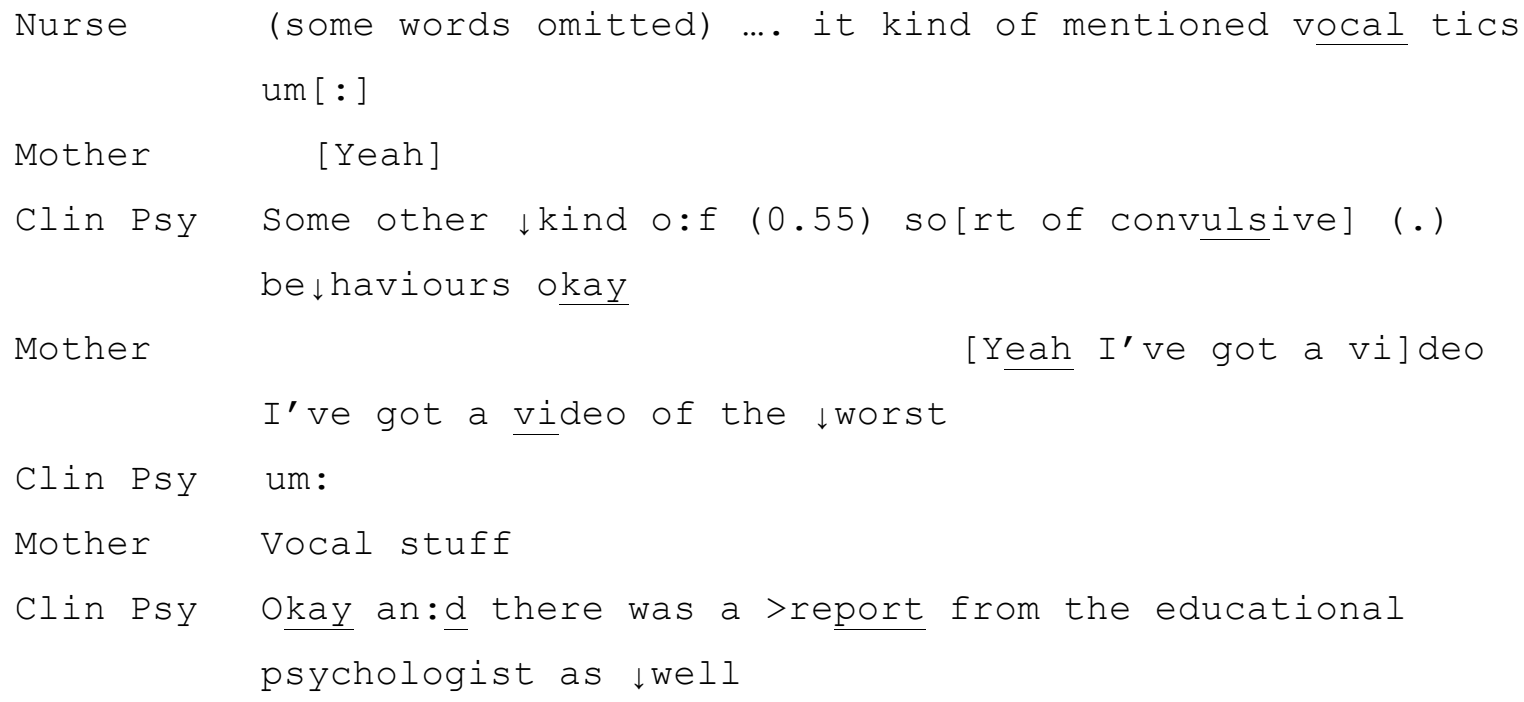

The mother's offer of physical evidence of a video of vocal behaviour 'I've got a video' occurred within a series of turns in which the psychologist was summarising written evidence provided by the GP 'we've had the referral from the GP' and the educational psychologist ' $a$ report from the educational psychologist'. This reporting of external expertise and evidence summarised the case being presented to the clinical team from outside sources. As previously discussed the use of epistemic corroboration carries significant weight for case building when presented by families, and here the practitioners oriented to the value of this in informing potential outcomes. Although drawing on epistemic information is a strong device for case building and was offered by the practitioner, the mother interrupted this presentation by offering additional objective video evidence.

In this situation, the mother offered agreement with the initial assessment summary of the referral, i.e., that vocal tics are a relevant part of the case. However, while the mother's turn functioned as a 'second assessment' (Pomerantz, 1984), CA suggests that for agreements to be treated as effective they require some upgrade otherwise they risk being treated as tacit disagreement (Schegloff, 1997). Rhetorically the mother was not only responding to the description of the GP's referral by the psychologist and has therefore not initiated the case at this point but aligned with the notion of vocal tics being an issue, upgrading the focus on those tics. In this way it was presented as an upgrade and corroboration of the case being built. Furthermore, one of the features of a successful epistemic upgrade in a second assessment position is the presentation of an independently held view (Raymond and Heritage, 2006). In this extract the 'independence' or objectivity of the evidence was provided in the form of a recording. 


\section{Discussion}

The use of persuasion and rhetoric to build cases is common in many different institutional settings, including journalism, court rooms, and medicine. Within the institutional context of child mental health assessments, the goal of ascertaining the presence or absence of a mental health condition is collaboratively achieved by family members and mental health practitioners. Often families have waited a significant period (sometimes several years) (Shanley et al., 2008) and therefore there is a lot at stake within this single appointment. For example, validation of the difficulties encountered by the family or potential judgement on parenting skills, and support and treatment for the child. Within this environment there is arguably a need for families to build a case and present a doctorable reason for attendance. This is especially evident in mental health clinics as outcomes generally rely on clinical judgement and language (Ziolkowska, 2009). This is complicated in those situations where different family members provide different accounts of events, sometimes in alignment and sometimes in disagreement, and the institutional objective for practitioners is to assess these discursive versions and provide a decision.

In the process of case building for a doctorable condition, in this study we demonstrated that parents and other family members, used a range of rhetorical devices to strengthen their claims. By utilising these rhetorical devices families worked to strengthen their claims and authenticate the case being built. The overall function of these multiple devices was to present a case that was persuasive and could potentially influence the professional's decision that the child required input from clinicians within the CAMHS context. Indeed, persuasion is a central mechanism for constructing and reconstructing social facts as part of the ongoing social process (Payne, 2001), in this case the assessment.

Our findings have parallels with other medical institutional environments, whereby patients solicit certain courses of treatment from the provider. CA studies have illustrated some of the rhetorical and persuasive devices utilised by patients when seeking antibiotics; for example, the alternative outcome that professionals orient to is the possibility of 'no treatable problem' which tacitly suggests that the patient's medical presentation may not need antibiotic treatment (Peräkylä, 2006). What was at stake for the families in our study is that there was a risk that the mental health practitioner may conclude that the child does not have a treatable 
problem. Thus, it is this potential conclusion that the rhetorical devices function to mitigate or discourage.

In conclusion, the data illustrated that family members built cases for the doctorable reason for presenting in clinic. The presence of the social action of case building highlights that families treated these assessment appointments as environments in which persuasive strategies were necessary. In other words, they oriented to the possibility that their case may be counterable and therefore had stake in presenting their accounts as factual, neutral and objective. Importantly, these multiple rhetorical devices were often combined together and throughout the appointment, with the case being built in an incremental and collaborative way. 


\section{References}

Billig M (1987) Arguing and thinking: A rhetorical approach to social psychology. New York: Cambridge University press.

Billig M (1988) Rhetorical and historical aspects of attitudes: the case of the British monarchy. Philosophical Psychology, 1, 83-103.

Condor S Tileaga C \& Billig M (2013) Political rhetoric. Oxford University Press.

Clift, R (2001) Meaning in interaction: The case of actually. Language, 245-291

Department of Health (2015) Future in Mind - promoting, protecting and improving our children and young people's mental health and wellbeing. London: Department of Health

Drew P Chatwin J \& Collins S (2001) Conversation analysis: A method for research into interactions between patients and health-care professionals. Health Expectations, 4(1), 58-70.

Drew P \& Holt E (1988) Complainable matters: The use of idiomatic expressions in making complaints. Social problems, 35(4), 398-417

Edwards D (1995) Two to tango: Script formulations, dispositions, and rhetorical symmetry in relationship troubles talk. Research on Language and Social Interaction, 28(4), 319-350.

Hartzell M Seikkula J \& von Knorring A (2010). Parent's perception of their first encounter with child adolescent psychiatry. Contemporary Family Therapy, 32, 273-289.

Hepburn A \& Bolden G (2017) Transcribing for social research. London, UK: Sage.

Heritage J (2012) Epistemics in action: Action formation and territories of knowledge. Research on Language and Social Interaction, 45, 1-29.

Heritage J \& Robinson J (2006) Accounting for the visit: giving reasons for seeking medical care. In J. Heritage \& D. Maynard (Eds). Communication in Medical Care: Interaction 
between Primary Care Physicians and Patients. (pp: 48-85). Cambridge: Cambridge University Press.

Holt E (1996) Reporting on talk: the use of direct reported speech in conversation. Research on Language and Social Interaction, 29, 219-245

Howard C Burton M Levermore D \& Barrell R (2017) Children's mental health and emotional well-being in primary schools. London: Learning Matters

Hutchby I (2001) Witnessing: The use of first-hand knowledge in legitimating lay opinions on talk radio. Discourse Studies, 3(4), 481-497.

Hutchby I \& Wooffitt R (2008) Conversation analysis ( $2^{\text {nd }}$ edition). Oxford: Blackwell Publishers.

Jefferson G (2004) Glossary of transcript symbols with an introduction, in G. Lerner, (Ed). Conversation analysis: Studies from the first generation. Ansterdam: John Benjamins Publishing company.

Karim K (2015) The value of conversation analysis: A child psychiatrist's perspective. In M O'Reilly \& J. N. Lester (Eds.), The Palgrave handbook of child mental health: Discourse and conversation studies (pp: 25-41). Basingstoke: Palgrave MacMillan.

Kastely A (1988) Unification and community: A rhetorical analysis of the United Nations Sales Convention Symposium. Northwestern Journal of International Law \& Business 8,574

Kessler R Berglund O Demler R Jin \& Walters E (2005) Lifetime Prevalence and Age-ofOnset Distributions of DSM-IV Disorders in the National Comorbidity Survey Replication. Archives of General Psychiatry 62, 593-602.

Kieling C Baker-Henningham H Belfer M Conti G et al (2011) Child and adolescent mental health worldwide: Evidence for action. Lancet, 378, 1515-1525. 
Kiyimba N Lester J \& O’Reilly M (2019) Using naturally occurring data in health research: A practical guide. Springer

Lester J \& O’Reilly M (2019) Applied conversation analysis: Social interaction in institutional settings. Thousand Oaks, CA: Sage.

Mash E and Hunsley (2005) Developing guidelines for the evidence-based assessment of child and adolescent disorders. Journal of Child and Adolescent Psychology, 34 (3), 362-379.

NHS Digital (2018) Mental health of children and young people in England, 2017: Summary of key findings. As retrieved $11^{\text {th }}$ December 2018 from:

https://files.digital.nhs.uk/F6/A5706C/MHCYP\%202017\%20Summary.pdf

O’Reilly M Karim K Stafford V \& Hutchby I (2015). Identifying the interactional processes in the first assessments in child mental health. Child and Adolescent Mental Health, 20(4), 195-201.

O’Reilly M \& Kiyimba N (2015) Advanced qualitative research: A guide to contemporary theoretical debates. London: Sage.

O'Reilly M \& Lester J (2017) Examining mental health through social constructionism: The language of mental health. Basingstoke: Palgrave.

Payne R (2001) Persuasion, frames and norm construction. European journal of international relations, 7(1), 37-61.

Peräkylä A (2006). Communicating and responding to diagnosis. In J. Heritage \& D. Maynard (Eds.), Communication in medical care: Interactions between primary care physicians and patients (pp. 214-247). Cambridge, England: Cambridge University Press

Pomerantz A (1984). Agreeing and disagreeing with assessments: some features of preferred/dispreferred turn shapes. In J. M. Atkinson, \& J. Heritage, (Eds). Structures of social action: studies in conversation analysis. (pp: 57 - 101). Cambridge: Cambridge University Press. 
Pomerantz A (1986) Extreme case formulations: A way of legitimising claims. Human Studies, 9, 219-229.

Potter J (1996) Discourse analysis and constructionist approaches: Theoretical background. British Psychological Society.

Potter J (1996 b). Representing Reality. London: Sage.

Potter J (2002) Two kinds of natural. Discourse Studies. 4 (4), 539-542.

Porter T (1996). Trust in numbers: The pursuit of objectivity in science and public life. Princeton University Press.

Raymond G \& Heritage J (2006) The epistemics of social relations: Owning grandchildren. Language in Society, 35(5), 677-705.

Sacks H (1992) Jefferson, G. Lectures in conversation. Volume 1. Oxford: Blackwell

Sacks S (2004) Pre-announcement sequences in conversation. Conversation analysis: Studies from the first generation, 125, 171.

Sacks H Schegloff E \& Jefferson G (1974). A simplest systematics for the organization of turn-taking for conversation. Language, 50, 696-735

Schegloff E (1997) Whose text? Whose context? Discourse \& Society, 8(2), 165-187.

Schiffrin D (1985) Everyday argument: the organisation of diversity in talk. In van Dijk, T.A. (Ed.), Handbook of Discourse Analysis. London: Academic Press.

Schegloff E (1996) Turn organization: One intersection of grammar and interaction. In Ochs et al., 52-133.

ten Have, P (2001) Lay diagnosis in interaction. Text, 21 (1/2), 251-260. 
Thompson L \& McCabe R (2016) 'Good' communication in schizophrenia: a conversation analytic definition. In M O'Reilly \& J.N. Lester (Eds.), The Palgrave handbook of adule mental health: Discourse and conversation studies (pp: 394-418). Basingstoke: Palgrave MacMillan.

Weare K (2000) Promoting mental, emotional and social health: A whole school approach. London: Routledge

White J (1984) When words lose their meaning: constitutions and reconstitutions of language, character, and community.

Wiggins S and Potter J (2008) Discursive psychology. In C. Willig and W. Stainton-Rogers (Eds.), The Sage handbook of qualitative research in psychology. London: Sage.

Wooffitt R (1991) '1 was just doing X... when Y': Some inferential properties of a device in accounts of paranormal experiences. Text-Interdisciplinary Journal for the Study of Discourse, 11(2), 267-288.

Wooffitt R (2001) Raising the Dead: Reported Speech in Medium-Sitter Interaction. Discourse Studies, 3(3), 351-374.

Ziolkowska J (2009) Positions in doctors' questions during psychiatric interviews. Qualitative Health Research, 19 (11), 1621-1631. 